Brodersen, Kai; Fuchs, Thomas [Hrsg.]; Universitäts-Gesellschaft <Heidelberg> [Hrsg.]: Heidelberger Jahrbücher: Wahn Welt Bild: die Sammlung Prinzhorn ; Beiträge zur Museumseröffnung

\title{
Hans Prinzhorn - ein „Sinnender“ in der Weimarer Republik
}

\author{
THOMAS RösKe
}

\section{Einleitung}

Hans Prinzhorn sympathisierte zwischen 1930 und 1933 mit den Nationalsozialisten. Deshalb wurde in letzter Zeit von verschiedener Seite der Vorwurf erhoben, er sei Faschist gewesen. Und es wurde kritisiert, dass man ihn heute durch die Verbindung seines Namens mit der Sammlung und durch die Feierlichkeiten und Veranstaltungen zur Eröffnung des Museums ehre. Die Tagung kann an diesem Vorwurf nicht vorbeigehen, auch wenn es hier primär um Prinzhorns Jahre in Heidelberg von 1919 bis 1921 geht, die er selbst als seine „Steinzeit“ bezeichnet hat. ${ }^{1}$ So soll der Versuch gemacht werden, den Prinzhorn vom Anfang der Weimarer Republik aus der Perspektive des Prinzhorn vom Ende dieses dramatischen Abschnitts deutscher Geschichte zu betrachten.

Um es gleich vorweg zu nehmen: Dabei wird keine Deckungsgleichheit mit der Position des berüchtigten Carl Schneider offenbar. Von diesem trennen Prinzhorn ideologische Welten in der Einschätzung künstlerischer Werke von Patientinnen und Patienten psychiatrischer Einrichtungen. ${ }^{2}$ Prinzhorn hat die Artefakte dieser Menschen gerade nicht primär unter dem Aspekt Krankheit betrachtet; selbst ihre Eignung als differentialdiagnostisches Hilfsmittel stellte er in Frage. ${ }^{3}$ Und der Absicht, mit ihrer Hilfe zeitgenössische Kunst zu diffamieren, die schon vor den Nazis eine Reihe von Wissenschaftlern verfolgte, ${ }^{4}$

\footnotetext{
' Das berichtet Elsbeth Gnügge in einem Brief an Walter Ritter von Baeyer, Berlin, den 3.12.1966 (Archiv der Sammlung Prinzhorn, Heidelberg).

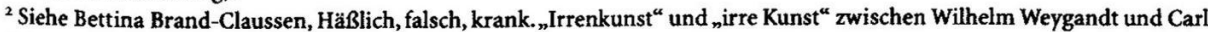
Schneider, in: Psychiatrische Forschung und NS- ${ }_{n}$ Euthanasie“. Beiträge zu einer Gedenkveranstaltung an der Psychiatrischen Universitätsklinik Heidelberg, hrsg. von Christoph Mundt, Gerrit Hohendorf und Maike Rotzoll, Heidelberg 2001, 265-329, hier S. 285-289.

${ }^{3}$ Hans Prinzhorn, Bildnerei der Geisteskranken. Ein Beitrag zur Psychologie und Psychopathologie der Gestaltung, Berlin 1922, S. 337.

4 Siehe Brand-Claussen 2001, wie Anm. 2.
} 